OPEN ACCESS

Edited by: Nicola Silvestris,

University of Bari Aldo Moro, Italy

Reviewed by:

Luca Falzone,

Istituto Nazionale Tumori Fondazione

G. Pascale (IRCCS), Italy

Airton T. Stein,

Federal University of Health Sciences

of Porto Alegre, Brazil

*Correspondence: Kashif Asghar

kashifasghar@skm.org.pk

Specialty section:

This article was submitted to

Cancer Epidemiology and Prevention,

a section of the journal

Frontiers in Oncology

Received: 22 January 2021

Accepted: 15 April 2021

Published: 20 May 2021

Citation:

Asghar K, Abu Bakar M, Akram MJ,

Farooq A, Siddique K, Rana IA, Ali J,

Rashid MU, Khan AA and Loya A

(2021) Clinical Characteristics of

COVID-19-Infected Cancer Patients in

Pakistan: Differences Between

Survivors and Non-Survivors.

Front. Oncol. 11:655634.

doi: 10.3389/fonc.2021.655634

\section{Clinical Characteristics of COVID-19-Infected Cancer Patients in Pakistan: Differences Between Survivors and Non-Survivors}

\author{
Kashif Asghar ${ }^{1 *}$, Muhammad Abu Bakar ${ }^{2}$, Muhammad Junaid Akram ${ }^{3}$, Asim Farooq $^{4}$, \\ Kashif Siddique ${ }^{5}$, Iftikhar Ali Rana ${ }^{6}$, Jamshed Ali ${ }^{7}$, Muhammad Usman Rashid ${ }^{1}$, \\ Ashraf Ali Khan ${ }^{8}$ and Asif Loya ${ }^{6}$ \\ ${ }^{1}$ Department of Basic Sciences Research, Shaukat Khanum Memorial Cancer Hospital and Research Centre, \\ Lahore, Pakistan, ${ }^{2}$ Department of Cancer Registry and Clinical Data Management, Shaukat Khanum Memorial Cancer \\ Hospital and Research Centre, Lahore, Pakistan, ${ }^{3}$ Department of Internal Medicine (Pulmonology), Shaukat Khanum \\ Memorial Cancer Hospital and Research Centre, Lahore, Pakistan, ${ }^{4}$ Department of Clinical Research, Shaukat Khanum \\ Memorial Cancer Hospital and Research Centre, Lahore, Pakistan, ${ }^{5}$ Department of Radiology, Shaukat Khanum Memorial \\ Cancer Hospital and Research Centre, Lahore, Pakistan, ${ }^{6}$ Department of Pathology, Shaukat Khanum Memorial Cancer \\ Hospital and Research Centre, Lahore, Pakistan, ${ }^{7}$ Department of Medical Oncology, Shaukat Khanum Memorial Cancer \\ Hospital and Research Centre, Peshawar, Pakistan, ${ }^{8}$ Department of Internal Medicine (Infectious Diseases), Shaukat \\ Khanum Memorial Cancer Hospital and Research Centre, Lahore, Pakistan
}

Background: Cancer patients are considered as highly vulnerable individuals in the current COVID-19 pandemic. We studied the clinical characteristics of survivor and nonsurvivor COVID-19-infected cancer patients in Pakistan.

Patients and Methods: We did a retrospective study of 70 cancer patients with PCRconfirmed COVID-19 infection from Shaukat Khanum Memorial Cancer Hospital and Research Centre, Lahore and Peshawar, Pakistan between April 13 and July 09, 2020. These patients were discharged from the hospital or had died by July 09, 2020. Clinical, pathological and radiological characteristics were compared between survivors and nonsurvivors by fisher's exact test and chi-square test. Univariable and multivariable logistic regression models were performed to explore the risk factors of mortality.

Results: Seventy cancer patients with SARS-CoV-2 infection were enrolled and the majority were males 38 (54.3\%). 57 (81.4\%) had solid tumors and 13 (18.6\%) had hematological malignancies. Dyspnea (44 cases) was the most common symptom (62.9\%). Complications were reported in 51 (72.9\%) patients during the course of disease. 19 (27.1\%) patients were admitted to an intensive care unit (ICU). A significant increase in the C-reactive protein level and neutrophil count was observed in the deceased patients as compared to the surviving patients. D-dimer values of $\geq 0.2 \mathrm{mg} / \mathrm{L}$ were significantly associated with mortality $(P=0.01)$. We identified two independent risk factors associated with death, ICU admission $(P=0.007)$ and D-dimer $(P=0.003)$. 


\begin{abstract}
Conclusion: Pakistani cancer patients with COVID-19 infection reported poor prognosis. Intensive surveillance of clinicopathological characteristics of cancer patients infected with COVID-19 especially D-dimer values may play a pivotal role in the outcome of the disease.
\end{abstract}

Keywords: COVID-19, cancer, survivors, Pakistan, non-survivors

\section{INTRODUCTION}

The coronavirus disease of 2019 (COVID-19) is caused by severe acute respiratory syndrome coronavirus 2 (SARS-CoV-2) (1). The virus was first detected in December 2019, in Wuhan, China (2). The whole world including Pakistan is experiencing COVID19 outbreaks (3). The World Health Organization (WHO) declared the COVID-19 outbreak a pandemic on March 11, 2020 (4). As of March 11, 2021, 117,160,237 cases have been confirmed worldwide, with 2,598,892 deaths (5). In Pakistan 597,497 COVID-19, cases and 13,377 deaths have been confirmed, as of March 12, 2021 (6).

Epidemiological data have indicated that cancer patients are more susceptible to the COVID-19 infection (7-11). SARS-CoV2 infection affects the functioning of cardiovascular, renal, hepatic, pancreatic and gastrointestinal systems (8). Furthermore, the virus has the ability to invade and cause neural disease in the central and peripheral nervous system $(8,12)$. There is an increased risk of opportunistic infections in cancer patients due to their impaired immunity, poor nutrition and post cancer therapy associated side effects (7). Liang et al. demonstrated that cancer patients with COVID-19 had poorer outcomes (13). Zhang et al. also reported that cancer patients with COVID-19 showed poor prognoses (14). Comprehensive data published by Yang and colleagues concluded that patients with cancer and COVID-19 are a high-risk population with an increased mortality rate (7).

Each year around 200,000 new cancer cases are being diagnosed in Pakistan (15) and approximately, 45,000 cancer patients come to the Shaukat Khanum Memorial Cancer Hospital and Research Centre (SKMCH \& RC). SKMCH \& RC is a state-of-the-art charitable hospital where $75 \%$ of patients diagnosed with cancer are treated free of charge (16). The hospital also accepts cancer patients from Afghanistan.

We analyzed the data from cancer patients with SARS-CoV-2 infection who were admitted to SKMCH \& RC. Here, we report the systematically characterized clinical features of survivors and non-survivors COVID-19-infected cancer patients in Pakistan, in an attempt to define the nature of the aggravating factors caused by COVID-19 infection.

\section{METHODS}

\section{Study Design and Participants}

The current study was conducted at SKMCH \& RC Lahore and Peshawar, Pakistan. This is a retrospective cohort study. The first cases of SARS-CoV-2 were identified in Pakistan in February 2020 (3). Immediately after the COVID-19 outbreak, SKMCH \&
RC Lahore and Peshawar initiated the diagnosis and treatment of SARS-CoV-2 infected cancer patients. COVID-19 patients were diagnosed based on the guidelines provided by WHO (17). All enrolled patients had previously been diagnosed with cancer. We included all patients (aged $\geq 18$ years) with pathological diagnoses of any malignant solid or hematological malignancies along with PCR-confirmation of SARS-CoV-2 infection. We aimed to investigate the clinical characteristics of survivors and non-survivors COVID-19-infected cancer patients in Pakistan. All patients fulfilling the eligibility criteria were included in the study. The study cutoff date was July 09, 2020. The institutional review board (IRB) of SKMCH \& RC approved the current study (IRB-EX-20-04-20-01). IRB granted the waiver of the written informed consent from study participants.

\section{Data Collection}

The information about the demographic data, clinicopathological characteristics, laboratory findings and chest X-ray examinations were acquired from pathology and radiology reports from our hospital medical records' system. Data about gender, age, comorbidities (diabetes, hypertension, cardiac disease, chronic pulmonary disease, chronic kidney disease and chronic liver disease), cancer history (cancer type, stage and treatment), vital signs (temperature, heart rate, respiratory rate, blood oxygen saturation), body mass index and symptoms (dyspnea, cough, fever, muscle ache, sore throat, diarrhea, vomiting, chills, abdominal pain and headache) and pathology lab tests (white blood cells, neutrophils, lymphocytes, platelets, red blood cells, hemoglobin, creatinine, blood urea nitrogen, lactate dehydrogenase, lactate, $\mathrm{pH}, \mathrm{PCO} 2, \mathrm{PO} 2, \mathrm{HCO} 3, \mathrm{O} 2$ saturation, alanine transaminase (ALT), aspartate transaminase (AST), albumin, globulin, gamma-glutamyl transpeptidase (GGT), alkaline phosphatase, C-reactive protein, ferritin and D-dimer) were all obtained at the time of diagnosis of COVID-19 in cancer patients. According to the TNM staging system, cancers were defined as stages I, II, III and IV. We also collected the information about treatments for cancer patients with COVID19 (intravenous antibiotics, antiviral therapy, immunotherapy, anthelmintic agent, montelukast, hydroxychloroquine, zinc/ vitamin- $C$, continuous renal replacement therapy, oxygen therapy and mechanical ventilation), complications and outcomes during admission to hospital.

\section{Statistical Analysis}

We hypothesized that differences exist in demographic, clinical, and laboratory characteristics, treatments, and cancer history between survivors and non-survivors of COVID-19 with cancer. Quantitative variables were presented as medians/mean (range: minimum-maximum/standard deviation), and qualitative 
variables were presented by frequencies and percentages. The independent t-test, Mann-Whitney U test, Chi-square test, and Fisher's exact test were applied to analyze the differences between groups according to the type of data. Kaplan-Meier analysis (logrank test) was used to check the survival difference. Risk factors associated with death and their odds ratios (ORs) were analyzed by the univariable logistic regression model. Variable selection for multivariable analysis was based on significance from the univariable logistic regression analysis $(\mathrm{p}<0 \cdot 05)$. We used IBM SPSS Statistics 20.0 software for statistical analysis. The tests we used were all two-sided with less than 5\% type I error. The differences between groups were considered to be significant when the $P$-value was less than 0.05 .

\section{RESULTS}

From April 13 to July 09, 2020, 13,692 patients were diagnosed with COVID-19 in an electronic medical record system from SKMCH\&RC, Pakistan. Among 13,692 patients, 443 (3.23\%) had cancer. 81 patients with COVID-19 symptoms were admitted at SKMCH\&RC. After excluding 11 patients (under the age of 18 years), we included only 70 (15.80\%) out of 443 hospital admitted cancer patients as shown in (Supplementary Figure 1). None of the 70 patients was lost to follow-up during the hospital admission. Of the 70 cancer patients $30(42.9 \%)$ had died as of July 9, 2020, including, $22(73.33 \%)$ patients who belonged to the Punjab province. The primary cause of death was COVID-19 infection in these patients. $38(54.3 \%)$ patients were male, 32 (45.7\%) patients were female, and overall follow-up for all the patients was 88 days. The overall mean age was $50.27 \pm 16.61$ (Table 1). Approximately two-thirds of the patients (72.85\%) were admitted to the hospital within 24 hours after diagnosis. 67 (95.71\%) of 70 patients had symptoms during the course of COVID-19.

Dyspnea (62.9\%), cough (57.1\%) and fever (34.3\%) were the most common symptoms, followed by muscle ache (31.4\%), sore throat $(24.3 \%)$, diarrhea (12.9\%), vomiting (12.9\%), chills (8.6\%), abdominal pain $(7.1 \%)$ and headache $(4.3 \%)$ (Table 1). The cancer patients also had other comorbidities, including diabetes (12.9\%), hypertension (20.0\%) and chronic pulmonary (11.4\%), kidney (10.0\%), heart (4.3\%) and liver (4.3\%) diseases (Table 1). Non-survivor patients had higher respiratory rates and lower levels of blood oxygen saturation ( $\mathrm{SpO} 2)$ as compared to the survivors. Dyspnea was the most common feature of nonsurvivor as compared to the survivor $(P=0.01)$. No significant differences in age, gender and other comorbidities were detected among survivors and non-survivors groups.

We found significantly elevated levels of $\mathrm{D}$-dimers in the nonsurvivors as compared to the survivors $(P=0.01)$. Furthermore, the non-survivor patients presented with higher levels of neutrophils $(P=0.01)$, creatinine $(P=0.02)$, blood urea nitrogen $(P=0.01)$, lactate $(P=0.02)$, aspartate transaminase $(P=0.02)$ and ferritin $(P=0.03)$ compared to survivor patients. Additionally, C-reactive protein level and neutrophil-lymphocyte ratio (NLR) was higher in the non-survivors than survivors $(P=0.01)$, (Table 2).
$54(77.14 \%)$ out of 70 patients showed abnormal features in the radiological findings (Supplementary Figure 2). 23 (32.9\%) of 70 patients had ground-glass opacities, and $12(17.1 \%)$ presented with consolidation (Table 2).

Of the 70 patients included, 67 (95.7\%) received intravenous antibiotics and $1(1.4 \%)$ received antiviral medication (Table 3 ). Montelukast was given to $47(67.1 \%)$ patients. Ivermectin was given to $6(8.6 \%)$ patients. $41(58.6 \%)$ received Zinc and vitamin C. Hydroxychloroquine (HCQ) was given to 4 (5.7\%) patients. Tocilizumab was given to $12(17.1 \%)$ patients (Table 3). Invasive and non-invasive mechanical ventilation was provided to 19 (27.1\%) and 9 (12.9\%) patients, respectively. 19 (27.1\%) of 70 patients were admitted to the ICU. $51(72.9 \%)$ of 70 patients developed the complications. Additionally, 30 (58.82\%) of 51 patients having complications were non-survivors. We observed that non-survivors were more likely to receive oxygen therapy, required mechanical ventilation, were referred to the ICU, where they developed complications such as ARDS 32 (45.7\%), acute renal failure $23(32.9 \%)$, septic shock 22 (31.4\%), abnormal liver function 25 (35.7\%), coagulopathy16 (22.9\%), secondary infections $26(37.1 \%)$ and arrhythmia 8 (11.4\%), (Table 3).

$57(81.4 \%)$ of 70 patients were diagnosed with solid tumors and $13(18.6 \%)$ of 70 patients were diagnosed with hematological malignancies (Table 4). The most common cancers were in breast $11(19.3 \%)$, prostate 5 (8.8\%), colorectal 4 (7.0\%), lung 4 (7.0\%), kidney $3(5.3 \%)$ and oral $3(5.3 \%)$. Among hematological malignancies lymphoma (5cases:38.5\%) was most common. 53 (75.7\%) of 70 patients received the chemotherapy. Radiotherapy was given to $33(47.1 \%)$ of 70 patients. $25(35.7 \%)$ of 70 patients received chemotherapy within 4 weeks before the onset of symptoms. $23(32.9 \%)$ of 70 patients were diagnosed with cancer within the past year and $23(32.9 \%)$ of 70 patients had an ECOG score higher than the one before admission. 44 (72.1\%) of 70 patients were with an advanced stage (III-IV). The case fatality rate in patients with solid tumors was $40.3 \%$ (23 of 57 patients) and that in hematological malignancies was $53.8 \%$ (7 of 13 patients), (Table 4). The median time of hospital stay was 8 days (range 1-37 days). The overall median survival time of hospital stay was 19 days (confidence interval 13-25) Figure 1A. Overall survival was compared among the D-dimer categories, $<0.2$ and $\geq 0.2$. There was a statistically significant difference $(P=0.01)$ between the two groups (Figure 1B). The median survival time in $\mathrm{D}$-dimer was lowest in $\geq 0.2$ category (11 days with confidence interval 8-13) compared to D-dimer $<0.2$ category (26 days with confidence interval 13-39). Overall survival of $\mathrm{D}$-dimer $\geq 0.2$ category was significantly associated with mortality ( $P$-value 0.01$)$ as shown in Figure 1B.

In a univariable logistic regression model, dyspnea, respiratory rate, heart rate, ICU admission, creatinine, neutrophil, albumin, blood urea nitrogen, C-reactive protein and D-dimer values were associated with death. In addition, $\mathrm{SpO} 2$ and lactate were marginally statistically significant with respect to death in the univariable logistic regression model (Table 5). In a multivariable logistics regression model, we identified two variables as independent risk factors of death, ICU admission (odds ratio (OR), 21.79; 95\% confidence interval 
TABLE 1 | Demographics and baseline characteristics of patients with cancer and COVID-19.

\begin{tabular}{|c|c|c|c|c|}
\hline & Total $(n=70)$ & Alive $(n=40,57.1 \%)$ & Dead $(n=30,42.9 \%)$ & $P$-value \\
\hline \multicolumn{5}{|l|}{ Demographics } \\
\hline Age (years) & & & & 0.18 \\
\hline Mean \pm SD & $50.27 \pm 16.61$ & $47.98 \pm 15.98$ & $53.33 \pm 17.20$ & \\
\hline Sex & & & & 0.18 \\
\hline Male & $38(54.3 \%)$ & $19(47.5)$ & $19(63.3)$ & \\
\hline Female & $32(45.7 \%)$ & $21(52.5)$ & $11(36.7)$ & \\
\hline Geographic origin & & & & 0.20 \\
\hline Punjab & $53(75.7)$ & $31(77.5)$ & $22(73.3)$ & \\
\hline Khyber Pakhtunkhwa & $10(14.3)$ & $4(10.0)$ & $6(20.0)$ & \\
\hline Federally Administered Tribal Area & $1(1.4)$ & $0(0.0)$ & $1(3.3)$ & \\
\hline Afghanistan & $6(8.6)$ & $5(12.5)$ & 1 (3.3) & \\
\hline \multicolumn{5}{|c|}{ Clinical characteristics and outcomes } \\
\hline \multicolumn{5}{|l|}{ Comorbidities } \\
\hline Diabetes & $9(12.9)$ & $5(12.5)$ & $4(13.3)$ & 1.00 \\
\hline Hypertension & $14(20.0)$ & $8(20.0)$ & $6(20.0)$ & 1.00 \\
\hline Chronic pulmonary disease & $8(11.4)$ & $5(12.5)$ & $3(10.0)$ & 1.00 \\
\hline Chronic kidney disease & $7(10.0)$ & $3(7.5)$ & 4 (13.3) & 0.45 \\
\hline Coronary heart disease & $3(4.3)$ & $2(5.0)$ & 1 (3.3) & 1.00 \\
\hline Chronic liver disease & $3(4.3)$ & $2(5.0)$ & 1 (3.3) & 1.00 \\
\hline \multicolumn{5}{|l|}{ Symptoms } \\
\hline Dyspnea & $44(62.9)$ & $20(50.0)$ & $24(80.0)$ & 0.01 \\
\hline Cough & $40(57.1)$ & $25(62.5)$ & $15(50.0)$ & 0.29 \\
\hline Fever & $24(34.3)$ & $15(37.5)$ & $9(30.0)$ & 0.51 \\
\hline Muscle ache & $22(31.4)$ & $14(35.0)$ & $8(26.7)$ & 0.45 \\
\hline Sore throat & $17(24.3)$ & $11(27.5)$ & $6(20.0)$ & 0.46 \\
\hline Diarrhea & $9(12.9)$ & $3(7.5)$ & $6(20.0)$ & 0.15 \\
\hline Vomiting & 9 (12.9) & $4(10.0)$ & $5(16.7)$ & 0.48 \\
\hline Chills & $6(8.6)$ & $3(7.5)$ & $3(10.0)$ & 1.00 \\
\hline Abdominal pain & $5(7.1)$ & $3(7.5)$ & $2(6.7)$ & 1.00 \\
\hline Headache & $3(4.3)$ & $3(7.5)$ & $0(0.0)$ & 0.25 \\
\hline \multicolumn{5}{|l|}{ Temperature $\left({ }^{\circ} \mathrm{C}\right)$} \\
\hline Mean \pm SD & $37.32 \pm 0.85$ & $37.36 \pm 0.96$ & $37.26 \pm 0.69$ & 0.61 \\
\hline \multicolumn{5}{|l|}{ Heart rate (beats/min) } \\
\hline Mean \pm SD & $108.44 \pm 20.11$ & $104.25 \pm 18.81$ & $114.03 \pm 20.72$ & 0.04 \\
\hline \multicolumn{5}{|l|}{ Respiratory rate (breaths/min) } \\
\hline Mean \pm SD & $21.60 \pm 3.61$ & $20.67 \pm 3.46$ & $22.83 \pm 3.48$ & 0.01 \\
\hline \multicolumn{5}{|l|}{ SpO2 (\%) } \\
\hline Mean $\pm S D$ & $90.78 \pm 11.79$ & $93.32 \pm 6.62$ & $87.40 \pm 15.84$ & 0.03 \\
\hline \multicolumn{5}{|l|}{ Body mass index (BMI) } \\
\hline Mean \pm SD & $26.26 \pm 7.25$ & $27.47 \pm 7.34$ & $24.63 \pm 6.91$ & 0.10 \\
\hline
\end{tabular}

SD, standard deviation; SpO2, blood oxygen saturation.

(CI), 2.31-205.68, $P=0.007$ ) and $\mathrm{D}$-dimer values (OR, 26.67; 95\% CI, 2.97-239.30, $P=0.003$ ).

\section{DISCUSSION}

Cancer patients are considered as highly vulnerable individuals in the COVID-19 pandemic (7-11). These individuals are at high risk to develop serious illness once diagnosed with COVID-19 infection. The mortality rate is high as well in these individuals (7). In addition to the few studies recently reported from China, this is the first retrospective study conducted in Pakistan to illustrate the comparative analysis of clinical characteristics, treatment, radiological and laboratory findings of survivor and non-survivor COVID-19-infected cancer patients. In particular, we identified two variables as independent risk factors of death: ICU admission and D-dimer.
SARS-CoV-2 infection may lead to acute respiratory distress syndrome (18). Dyspnea (62.9\%), cough (57.1\%) and fever $(34.3 \%)$ are the most common symptoms as described in previous studies $(7,19)$. Liang et al. observed that old age and comorbidities were the major risk factors (13). This was not observed in our study and our results were similar to the study published by Yang et al. (7). We further observed abnormal respiratory rate, heart rate and blood oxygen saturation in the COVID-19-infected cancer patients. A retrospective study reported a link between hypoxemia $(\mathrm{SpO} 2<90 \%)$ and mortality in COVID-19 patients (20). We found a significant difference in $\mathrm{SpO} 2$ in survivors and non-survivors patients. Yang et al. observed higher respiratory rates and lower levels of blood oxygen saturation among non-survivors (7). Our results are in keeping with this study, as we also found a significant difference in respiratory rates in survivors and non-survivors COVID-19 infected cancer patients. 
TABLE 2 | Laboratory and Radiological findings of patients with cancer and COVID-19.

\begin{tabular}{|c|c|c|c|c|}
\hline & Total $(n=70)$ & Alive $(n=40,57.1 \%)$ & Dead $(n=30,42.9 \%)$ & $P$-value \\
\hline \multicolumn{5}{|c|}{ White blood cells, $\times 10^{3} \mathrm{cells} / \mu \mathrm{l}$} \\
\hline Median (range) & $8.41(0.11-433)$ & $6.73(0.23-433)$ & $10.68(0.11-122.82)$ & 0.12 \\
\hline \multicolumn{5}{|l|}{ Neutrophils, $\times 10^{3} \mathrm{cells} / \mu \mathrm{l}$} \\
\hline Median (range) & $6.69(1.08-21.52)$ & $4.83(1.08-21.52)$ & $8.93(1.70-21.21)$ & 0.01 \\
\hline \multicolumn{5}{|c|}{ Lymphocytes, $\times 10^{3}$ cells $/ \mu \mathrm{L}$} \\
\hline Median (range) & $1.14(0.20-116.02)$ & $1.12(0.20-34.12)$ & $1.15(0.22-116.02)$ & 0.78 \\
\hline \multicolumn{5}{|l|}{ NLR } \\
\hline Median (range) & 6.07 (0.05-93.14) & $4.49(0.34-21.10)$ & $7.31(0.05-93.14)$ & 0.01 \\
\hline \multicolumn{5}{|l|}{ Platelets, $\times 10^{3}$ cells $/ \mu \mathrm{L}$} \\
\hline Median (range) & $238(2-852)$ & $256(20-852)$ & $211(2-483)$ & 0.27 \\
\hline \multicolumn{5}{|l|}{ RBCs, $\times 10^{6}$ cells $/ \mu \mathrm{L}$} \\
\hline Median(range) & $4.04(2.08-11.30)$ & $4.06(2.37-11.30)$ & $3.81(2.08-5.54)$ & 0.34 \\
\hline \multicolumn{5}{|l|}{ Hemoglobin, g/dL } \\
\hline Median (range) & $10.65(3.97-15)$ & $11.90(3.97-14.60)$ & $10.10(5.10-15.0)$ & 0.06 \\
\hline \multicolumn{5}{|l|}{ Creatinine, $\mathrm{mg} / \mathrm{dL}$} \\
\hline Median (range) & $0.66(0.25-4.67)$ & $0.63(0.28-1.55)$ & $0.76(0.25-4.67)$ & 0.02 \\
\hline \multicolumn{5}{|c|}{ Blood urea nitrogen, mg/dL } \\
\hline Median (range) & $15.04(3.60-99.14)$ & $12.36(3.60-37.12)$ & $19.93(7.49-99.14)$ & 0.01 \\
\hline \multicolumn{5}{|c|}{ Lactate dehydrogenase, $\mathrm{U} / \mathrm{L}$} \\
\hline Median(range) & $380(172-759)$ & $389.50(172-759)$ & $365(194-531)$ & 0.80 \\
\hline \multicolumn{5}{|l|}{ Lactate, mg/dL } \\
\hline Median (range) & $17.70(6.80-106.07)$ & $15.00(6.80-39)$ & 19.65 (9.10-106.07) & 0.02 \\
\hline \multicolumn{5}{|l|}{$\mathrm{pH}$} \\
\hline Median(range) & $7.47(7.20-7.54)$ & $7.47(7.39-7.54)$ & $7.44(7.20-7.52)$ & 0.17 \\
\hline \multicolumn{5}{|l|}{ PCO2, $\mathrm{mmHg}$} \\
\hline Median(range) & $34(17-63)$ & $34.5(30-49)$ & $34(17-63)$ & 0.96 \\
\hline \multicolumn{5}{|l|}{ PO2, $\mathrm{mmHg}$} \\
\hline Median(range) & $76(31-231)$ & $79(50-152)$ & $74(31-231)$ & 0.68 \\
\hline \multicolumn{5}{|l|}{ HCO3, mmol/L } \\
\hline Median(range) & $25(10.08-37.50)$ & $25.30(19.40-31.10)$ & $23.30(10.08-37.50)$ & 0.20 \\
\hline \multicolumn{5}{|l|}{ O2 saturation, \% } \\
\hline Median(range) & $95(67-100)$ & 96.50 (88-99) & $95(67-100)$ & 0.54 \\
\hline \multicolumn{5}{|l|}{ ALT, U/L } \\
\hline Median(range) & $30.50(9-448)$ & $26(9-151)$ & $36.50(15-448)$ & 0.10 \\
\hline AST, U/L & & & & \\
\hline Median(range) & $45(16-1318)$ & $27(16-288)$ & $53(21-1318)$ & 0.02 \\
\hline Albumin, g/dL & & & & \\
\hline Median (range) & $3.29(1.70-4.74)$ & $3.52(1.98-4.74)$ & $2.85(1.70-3.71)$ & 0.001 \\
\hline Globulin, g/dL & & & & \\
\hline Median(range) & $3.25(1.82-4.50)$ & $3.25(1.82-4.25)$ & $3.29(2.00-4.50)$ & 0.98 \\
\hline GGT, U/L & & & & \\
\hline Median(range) & $54.50(13-611)$ & $37.50(13-434)$ & $58.50(30-611)$ & 0.07 \\
\hline Alkaline phosphate, $\mathrm{U} / \mathrm{L}$ & & & & \\
\hline Median(range) & $94(48-870)$ & $93(48-623)$ & $106.50(54-870)$ & 0.25 \\
\hline C-reactive protein, $\mathrm{mg} / \mathrm{l}$ & & & & \\
\hline Median(range) & $148(2-586.43)$ & $94(4-514)$ & $209.50(2-586.43)$ & 0.01 \\
\hline Ferritin, ng/mL & & & & \\
\hline Median(range) & 915 (63.40-21422) & $757(63.40-4056)$ & 1250 (81.20-21422) & 0.03 \\
\hline D-dimer, mg/L & & & & 0.01 \\
\hline$<0.2$ & $23(52.3)$ & $19(76.0)$ & $4(21.1)$ & \\
\hline$\geq 0.2$ & $21(47.7)$ & $6(24.0)$ & 15 (78.9) & \\
\hline Radiological findings & & & & 0.07 \\
\hline Ground-glass opacity & $23(32.9)$ & $11(27.5)$ & $12(40.0)$ & \\
\hline Consolidation & $12(17.1)$ & $4(10.0)$ & $8(26.7)$ & \\
\hline Patchy shadowing & $11(15.7)$ & $5(12.5)$ & $6(20.0)$ & \\
\hline Reticulonodular infiltrates & $7(10.0)$ & $6(15.0)$ & $1(3.3)$ & \\
\hline Others & $1(1.4)$ & $1(2.5)$ & $0(0.0)$ & \\
\hline Normal & $11(15.7)$ & $9(22.5)$ & $2(6.7)$ & \\
\hline Unknown & $5(7.1)$ & $4(10.0)$ & $1(3.3)$ & \\
\hline
\end{tabular}

NLR, neutrophil-lymphocyte ratio; RBCs, red blood cells; ALT, alanine transaminase; AST, aspartate transaminase; GGT, gamma-glutamyl transpeptidase.

In addition to previously reported data, D-dimers are usually elevated in patients with COVID-19 (21). Yao et al. observed an association of increased D-dimer level $(>2.14 \mathrm{mg} / \mathrm{L})$ with in- hospital mortality (21). Tian and colleagues showed that Ddimer might play a predictive role for COVID-19 severity particularly in cancer patients (22). Yang et al. also observed 
TABLE 3 | Treatments and complications of patients with cancer and COVID-19.

\begin{tabular}{|c|c|c|c|c|}
\hline & $\begin{array}{c}\text { Total } \\
(n=70)\end{array}$ & $\begin{array}{c}\text { Alive }(n=40, \\
57.1 \%)\end{array}$ & $\begin{array}{c}\text { Dead }(n=30 \\
42.9 \%)\end{array}$ & $\begin{array}{c}P \text { - } \\
\text { value }\end{array}$ \\
\hline \multicolumn{5}{|l|}{ Treatments } \\
\hline $\begin{array}{l}\text { Intravenous } \\
\text { antibiotic }\end{array}$ & $67(95.7)$ & 37 (92.5) & $30(100.0)$ & 0.25 \\
\hline Antiviral medication & $1(1.4)$ & $1(2.5)$ & $0(0.0)$ & 1.00 \\
\hline Tocilizumab & $12(17.1)$ & $4(10.0)$ & $8(26.7)$ & 0.06 \\
\hline Montelukast & $47(67.1)$ & $29(72.5)$ & $18(60.0)$ & 0.27 \\
\hline Ivermectin & $6(8.6)$ & $0(0.0)$ & $6(20.0)$ & 0.05 \\
\hline Zinc (vitamin C) & $41(58.6)$ & $25(62.5)$ & $16(53.3)$ & 0.44 \\
\hline $\mathrm{HCQ}$ & $4(5.7)$ & $2(5.0)$ & $2(6.7)$ & 1.00 \\
\hline Oxygen therapy & $61(87.1)$ & $31(77.5)$ & $30(100.0)$ & 0.01 \\
\hline \multicolumn{5}{|l|}{$\begin{array}{l}\text { Mechanical } \\
\text { ventilator }\end{array}$} \\
\hline None & $42(60.0)$ & 35 (87.5) & 7 (23.3) & 0.001 \\
\hline Non-invasive & $9(12.9)$ & $3(7.5)$ & $6(20.0)$ & \\
\hline Invasive & $19(27.1)$ & $2(5.0)$ & $17(56.7)$ & \\
\hline ICU admission & $19(27.1)$ & $4(10.0)$ & $15(50.0)$ & 0.001 \\
\hline CRRT & $9(12.9)$ & $0(0.0)$ & $9(90.0)$ & 0.001 \\
\hline Complications & $51(72.9)$ & $21(52.5)$ & $30(100.0)$ & 0.001 \\
\hline ARDS & $32(45.7)$ & $6(15.0)$ & $26(86.7)$ & 0.001 \\
\hline Acute renal failure & $23(32.9)$ & $2(5.0)$ & $21(70.0)$ & 0.001 \\
\hline Septic shock & $22(31.4)$ & $3(7.5)$ & 19 (63.3) & 0.001 \\
\hline $\begin{array}{l}\text { Abnormal liver } \\
\text { function }\end{array}$ & $25(35.7)$ & $9(22.5)$ & $16(53.3)$ & 0.001 \\
\hline Coagulopathy & $16(22.9)$ & $1(2.5)$ & $15(50.0)$ & 0.001 \\
\hline Secondary infection & $26(37.1)$ & $7(17.5)$ & 19 (63.3) & 0.001 \\
\hline Arrhythmia & $8(11.4)$ & $1(2.5)$ & 7 (23.3) & 0.01 \\
\hline Other complications & $22(31.4)$ & $11(27.5)$ & $11(36.7)$ & 0.41 \\
\hline
\end{tabular}

therapy; ARDS, acute respiratory distress syndrome.

elevated level of D-dimer in non-survivors as compared to survivors cancer patients with COVID-19 (7). We also found that higher levels of D-dimer $(\geq 0.2 \mathrm{mg} / \mathrm{L})$ were significantly different between non-survivor and survivor cancer patients infected with COVID-19. Additionally, D-dimers $\geq 0.2$ was significantly associated with mortality. In this regard, the first post-mortem analysis of COVID-19 microscopic lesions reported by Varga et al. showed direct viral involvement of endothelial structures (endothelialitis) (23), a phenomenon which may be linked with the coagulopathy (increase in Ddimers) observed in this study. These findings may justify the use of anti-viral or anti-COVID 19 antibody treatments to ameliorate the outcome of COVID-19-positive cancer patients.

Inflammatory cytokines are involved in the severity and adverse clinical outcomes in COVID-19 infected patients (24). Zhang et al. reported high neutrophil counts and C-reactive protein levels in cancer patients infected with COVID-19 (24). We also observed higher neutrophil counts and C-reactive protein levels in non-survivor $v s$ survivor cancer patients infected with COVID-19. There is a possibility that proinflammatory neutrophils and C-reactive protein induce "cytokine storm" related to endothelialitis caused by COVID19 infected cancer patients $(23,24)$. Serum lactate is used to assess the disease severity, therapeutic response and disease outcomes (25). Evaluating the lactate level has clinical significance in the management of critical cases of severe sepsis (26). Previously published data have shown that hyperlactatemia
TABLE 4 | History of cancer in patients with COVID-19.

\begin{tabular}{|c|c|c|c|c|}
\hline & $\begin{array}{c}\text { Total } \\
(\mathrm{n}=70)\end{array}$ & $\begin{array}{c}\begin{array}{c}\text { Alive } \\
(\mathrm{n}=40, \\
57.1 \%)\end{array}\end{array}$ & $\begin{array}{c}\text { Dead } \\
(n=30, \\
42.9 \%)\end{array}$ & $\begin{array}{c}P \text { - } \\
\text { value }\end{array}$ \\
\hline Cancer Type & & & & 0.37 \\
\hline Hematological malignancy & $13(18.6)$ & $6(15.0)$ & $7(23.3)$ & \\
\hline Acute lymphoblastic leukemia & $3(23.1)$ & $3(50.0)$ & $0(0.0)$ & \\
\hline Chronic lymphocytic leukemia & $2(15.4)$ & $1(16.7)$ & $1(14.3)$ & \\
\hline Chronic myeloid leukemia & $1(7.7)$ & $0(0.0)$ & $1(14.3)$ & \\
\hline Leukemia & $1(7.7)$ & $0(0.0)$ & $1(14.3)$ & \\
\hline Lymphoma & $5(38.5)$ & $2(33.3)$ & $3(42.9)$ & \\
\hline Multiple myeloma & $1(7.7)$ & $0(0.0)$ & $1(14.3)$ & \\
\hline Solid tumor & $57(81.4)$ & $34(85.0)$ & $23(76.7)$ & \\
\hline Breast & $11(19.3)$ & $7(20.6)$ & $4(17.4)$ & \\
\hline Prostate & $5(8.8)$ & $4(11.8)$ & $1(4.3)$ & \\
\hline Colorectal & $4(7.0)$ & $1(2.9)$ & $3(13.0)$ & \\
\hline Lung & $4(7.0)$ & $1(2.9)$ & $3(13.0)$ & \\
\hline Kidney & $3(5.3)$ & $1(2.9)$ & $2(8.7)$ & \\
\hline Oral & $3(5.3)$ & $2(5.9)$ & $1(4.3)$ & \\
\hline Others & $27(47.4)$ & 18 (52.9) & $9(39.1)$ & \\
\hline History of treatments & $62(88.6)$ & $38(95.0)$ & $24(80.0)$ & 0.06 \\
\hline Surgery & $40(57.1)$ & $26(65.0)$ & $14(46.7)$ & 0.12 \\
\hline Chemotherapy & $53(75.7)$ & $31(77.5)$ & $22(73.3)$ & 0.68 \\
\hline Radiotherapy & $33(47.1)$ & $22(55.0)$ & $11(36.7)$ & 0.12 \\
\hline \multicolumn{5}{|l|}{$\begin{array}{l}\text { Chemotherapy within } 4 \text { weeks } \\
\text { before symptoms onset }\end{array}$} \\
\hline Chemotherapy & $25(35.7)$ & $15(37.5)$ & $10(33.3)$ & 0.71 \\
\hline Cancer stage & & & & 0.19 \\
\hline Early (I-II) & $17(27.9)$ & $12(34.3)$ & $5(19.2)$ & \\
\hline Advance (III-IV) & $44(72.1)$ & $23(65.7)$ & $21(80.8)$ & \\
\hline Metastasis & $23(32.9)$ & $15(37.5)$ & $8(26.7)$ & 0.34 \\
\hline Time since cancer diagnosis & & & & 0.23 \\
\hline$<1$ & $23(32.9)$ & $15(37.5)$ & $8(26.7)$ & \\
\hline $1-5$ years & $36(51.4)$ & $17(42.5)$ & $19(63.3)$ & \\
\hline$>5$ & $11(15.7)$ & $8(20.0)$ & $3(10.0)$ & \\
\hline $\begin{array}{l}\text { ECOG performance status } \\
\text { score }\end{array}$ & & & & 0.35 \\
\hline 0 & 13 (18.6) & $10(25.0)$ & $3(10.0)$ & \\
\hline 1 & $23(32.9)$ & $13(32.5)$ & 10 (33.3) & \\
\hline 2 & 27 (38.6) & 15 (37.5) & $12(40.0)$ & \\
\hline 3 & $3(4.3)$ & $1(2.5)$ & $2(6.7)$ & \\
\hline 4 & $4(5.7)$ & $1(2.5)$ & $3(10.0)$ & \\
\hline
\end{tabular}

ECOG, Eastern Cooperative Oncology Group.

may be a predictor of death (27). In our results, we found a significant increase in the lactate levels of non-survivor COVID19 infected cancer patients. As COVID-19 disease severity changes rapidly, it is beneficial to identify the parameters of severity at initial stage. Several studies also identified higher levels of creatinine $(7,28)$, blood urea nitrogen $(7,28)$, aspartate transaminase $(29,30)$, and ferritin $(31)$, that are associated with the severity of COVID-19 infection. We also found elevated levels of creatinine, blood urea nitrogen, aspartate transaminase, and ferritin in non-survivor COVID-19 infected cancer patients.

$\mathrm{Xu}$ et al. reported bilateral lung lesions in 53 (59\%) of 90 patients (32). We found bilateral lung lesions in $70 \%$ of our data set, which was higher than reported previously (32). The involvement of the lungs suggests that cancer patients are more prone to severe pulmonary disease after COVID-19infection. Furthermore, we observed that non-survivors were significantly more likely to receive oxygen therapy, require mechanical ventilation, and be referred to the ICU. 


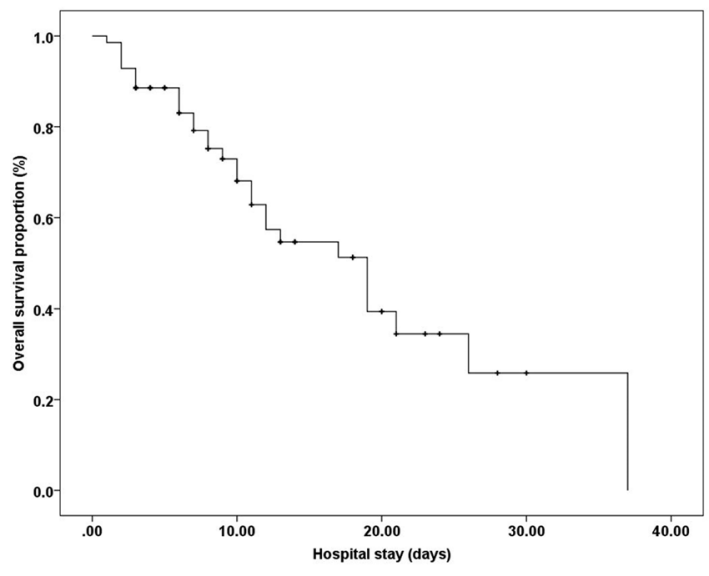

B

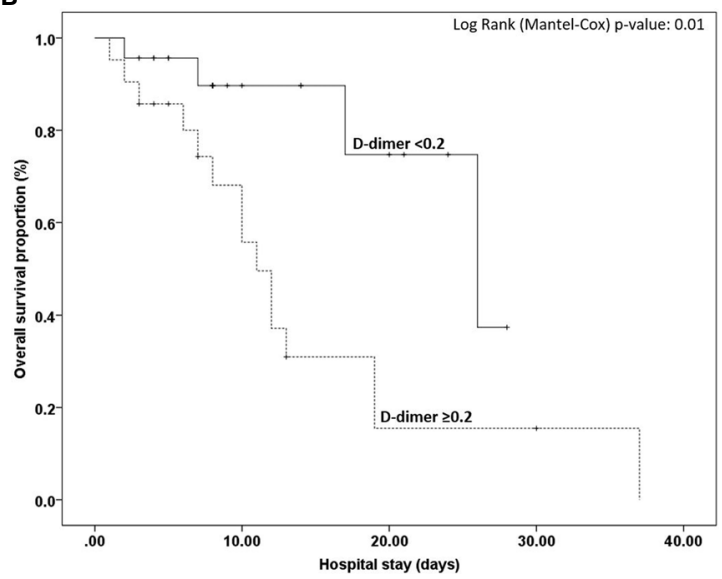

FIGURE 1 | (A) Overall Survival of COVID-19 cancer patients (B) Overall Survival of COVID-19 cancer patients stratified by two groups of D-dimer (<0.2 and $\geq 0.2)$.

Complications such as ARDS, acute renal failure, septic shock, coagulopathy, secondary infections and arrhythmia were common in these patients. Our results are in keeping with the data published previously (7). Yang et al. reported that COVID19 cancer patients receiving chemotherapy within 4 weeks before the onset of symptoms were more prone to death during hospital admission (7). In contrast, Lee et al. conducted a study on COVID-19 cancer patients and reported that chemotherapy had no effect on patient mortality (33). We found similar results with our limited retrospective cohort of COVID-19 infected cancer patients who received chemotherapy within 4 weeks before the onset of symptoms, which made no significant difference in mortality as compared to those who did not receive it. Clearly, a long-term follow up of the COVID-19 infected survivor cancer patients is required to identify the impact of the disease. The current study is a retrospective cohort, in which we included only those cancer patients who were admitted to our hospital from April 13 to July 9, 2020. The sample size of our

TABLE 5 | Adjusted logistic regression analysis of factors associated with mortality.

\begin{tabular}{|c|c|c|c|}
\hline Variables & Categories & $\begin{array}{l}\text { Univariable Odds ratio } \\
\text { (confidence interval), } P \text {-value }\end{array}$ & $\begin{array}{l}\text { Multivariable Odds ratio } \\
\text { (confidence interval), } P \text {-value }\end{array}$ \\
\hline Age (years) & Mean \pm SD & $1.02(1.00-1.05), 0.18$ & - \\
\hline Sex & Female & 0.52 (0.19-1.37), 0.19 & - \\
\hline BMI & Mean \pm SD & 0.94 (0.87-1.01), 0.11 & - \\
\hline \multirow[t]{2}{*}{ Dyspnea } & No & Ref & - \\
\hline & Yes & 4.00 (1.34-11.87), 0.01 & - \\
\hline Heart rate (beats/min) & Mean \pm SD & 1.02 (1.00-1.05), 0.04 & - \\
\hline \multirow[t]{2}{*}{ Comorbidity } & No & Ref & - \\
\hline & Yes & 0.96 (0.36-2.57), 0.94 & - \\
\hline \multirow[t]{2}{*}{ Cancer stage } & Early & Ref & - \\
\hline & Advance & $2.19(0.66-7.27), 0.20$ & - \\
\hline ICU admission & No & Ref & Ref \\
\hline Neutrophil, $\times 10^{3} \mathrm{cells} / \mathrm{\mu l}$ & Mean \pm SD & $1.14(1.03-1.28), 0.01$ & - \\
\hline Hemoglobin, g/dL & Mean \pm SD & 0.83 (0.67-1.02), 0.08 & - \\
\hline Albumin, $\mathrm{g} / \mathrm{dL}$ & Mean \pm SD & $0.10(0.02-0.40), 0.002$ & - \\
\hline Blood urea nitrogen, $\mathrm{mg} / \mathrm{dL}$ & Mean \pm SD & $1.08(1.02-1.15), 0.006$ & - \\
\hline C-reactive protein, mg/L & Mean \pm SD & $1.01(1.00-1.09), 0.01$ & - \\
\hline \multirow[t]{2}{*}{ D-dimer, mg/L } & $<0.2$ & Ref & Ref \\
\hline & $\geq 0.2$ & 11.87 (2.83-11.87), 0.001 & 26.67 (2.97-239.30), 0.003 \\
\hline
\end{tabular}

BMI, body mass index; SpO2, blood oxygen saturation; ICU, intensive-care unit. 
study was limited because we could not include all cancer patients who tested positive for COVID-19infection since the clinical and pathological data was available for admitted cancer patients only. In addition, we have not evaluated the alteration in hematological parameters during hospitalization. Another limitation of our study is that we could not include non-cancer patients since our hospital is a specialized cancer care hospital.

In conclusion, we provide comprehensive information of the clinical characteristics, laboratory data and outcomes of COVID-19infected cancer patients from Pakistan. This study highlights that elevated D-dimer levels and ICU admission as the two major independent risk factors for early surveillance of disease progression. Furthermore, we need to be more vigilant to the levels of C-reactive protein and neutrophils, once cancer patients are infected with COVID-19. The data presented in this study will certainly serve as a useful addition to the already available knowledge and to decide whether an anti-viral treatment is required or not. The risk factors might help clinicians to determine who are the high-risk cancer patients at the early onset of the infection.

\section{DATA AVAILABILITY STATEMENT}

The original contributions presented in the study are included in the article/Supplementary Material. Further inquiries can be directed to the corresponding author.

\section{ETHICS STATEMENT}

The studies involving human participants were reviewed and approved by Shaukat Khanum Memorial Cancer Hospital and

\section{REFERENCES}

1. Rothe C, Schunk M, Sothmann P, Bretzel G, Froeschl G, Wallrauch C, et al. Transmission of 2019-nCoV Infection From an Asymptomatic Contact in Germany. N Engl J Med (2020) 382:970-1. doi: 10.1056/NEJMc2001468

2. Holshue ML, DeBolt C, Lindquist S, Lofy KH, Wiesman J, Bruce H, et al. First Case of 2019 Novel Coronavirus in the United States. N Engl J Med (2020) 382:929-36. doi: 10.1056/NEJMoa2001191

3. Yusuf A. Cancer Care in the Time of COVID-19-a Perspective From Pakistan. Ecancermedicalscience (2020) 14:1026. doi: 10.3332/ecancer.2020.1026

4. WHO. Coronavirus Disease (COVID-19) Pandemic 2020. Available at: https:// www.who.int/emergencies/diseases/novel-coronavirus-2019 (Accessed assessed 07-Dec-2020).

5. European Center for Disease Prevention and Control. Available at: https:// www.ecdc.europa.eu/en/geographical-distribution-2019-ncov-cases (Accessed assessed 13-March-2021).

6. WHO. Available at: https://covid19.who.int/region/emro/country/pk (Accessed assessed 13-March-2021).

7. Yang K, Sheng Y, Huang C, Jin Y, Xiong N, Jiang K, et al. Clinical Characteristics, Outcomes, and Risk Factors for Mortality in Patients With Cancer and COVID-19 in Hubei, China: A Multicentre, Retrospective, Cohort Study. Lancet Oncol (2020) 21:904-13. doi: 10.1016/S1470-2045(20) 30310-7

8. Tsatsakis A, Calina D, Falzone L, Petrakis D, Mitrut R, Siokas V, et al. Sars-CoV-2 Pathophysiology and its Clinical Implications: An Integrative Overview of the Pharmacotherapeutic Management of COVID-19. Food Chem Toxicol (2020) 146:111769. doi: 10.1016/j.fct.2020.111769
Research Centre - Institutional Review Board (IRB). Written informed consent for participation was not required for this study in accordance with the national legislation and the institutional requirements.

\section{AUTHOR CONTRIBUTIONS}

KA had the idea for and designed the study. KA, MA, MJA, AF, $\mathrm{KS}$, IR, and JA were involved in the acquisition of the data. KA, MA, and MJA summarized the data. KA, MA, MJA, IR, JA, and KS were involved in data interpretation. KA drafted the manuscript. MA, KS, IR, JA, MR, AK, and AL critically revised the manuscript for important intellectual content. All authors contributed to the article and approved the submitted version.

\section{ACKNOWLEDGMENTS}

We would like to appreciate all hospital management and healthcare professionals who worked extensively during the pandemic. We also thank Prof. Dr. Daniel C. Hoessli for his valuable scientific input.

\section{SUPPLEMENTARY MATERIAL}

The Supplementary Material for this article can be found online at: https://www.frontiersin.org/articles/10.3389/fonc.2021. 655634/full\#supplementary-material

9. Vivarelli S, Falzone L, Grillo CM, Scandurra G, Torino F, Libra M. Cancer Management During COVID-19 Pandemic: Is Immune Checkpoint Inhibitors-Based Immunotherapy Harmful or Beneficial? Cancers (Basel) (2020) 12:2237. doi: 10.3390/cancers 12082237

10. Cavanna L, Citterio C, Toscani I, Franco C, Magnacavallo A, Caprioli S, et al. Cancer Patients With COVID-19: A Retrospective Study of 51 Patients in the District of Piacenza, Northern Italy. Future Sci OA (2020) 7:FSO645. doi: 10.2144/fsoa-2020-0157

11. Al-Quteimat OM, Amer AM. The Impact of the COVID-19 Pandemic on Cancer Patients. Am J Clin Oncol (2020) 43:452-5. doi: 10.1097/COC.0000000000000712

12. Pennisi M, Lanza G, Falzone L, Fisicaro F, Ferri R, Bella R. Sars-CoV-2 and the Nervous System: From Clinical Features to Molecular Mechanisms. Int J Mol Sci (2020) 21:5475. doi: 10.3390/ijms21155475

13. Liang W, Guan W, Chen R, Wang W, Li J, Xu K, et al. Cancer Patients in SARS-CoV-2 Infection: A Nationwide Analysis in China. Lancet Oncol (2020) 21:335-7. doi: 10.1016/S1470-2045(20)30096-6

14. Zhang L, Zhu F, Xie L, Wang C, Wang J, Chen R, et al. Clinical Characteristics of COVID-19-infected Cancer Patients: A Retrospective Case Study in Three Hospitals Within Wuhan, China. Ann Oncol (2020) 31:894-901. doi: 10.1016/ j.annonc.2020.03.296

15. International Agency for Research on Cancer Globocan. Pakistan Fact Sheet (2018). Available at: https://gco.iarc.fr/today/data/factsheets/populations/586pakistan-fact-sheets.pdf.

16. Asghar K, Loya A, Rana IA, Tahseen M, Ishaq M, Farooq A, et al. Indoleamine 2,3-Dioxygenase Expression and Overall Survival in Patients Diagnosed With Breast Cancer in Pakistan. Cancer Manag Res (2019) 11:475-81. doi: 10.2147/ CMAR.S184221 
17. WHO. Clinical Management of Severe Acute Respiratory Infection When Novel Coronavirus ( $\mathrm{nCoV}$ ) Infection is Suspected: Interim Guidance (2020). Available at: https://www.who.int/internalpublicationsdetail/clinical-management-ofsevere-acute-respiratoryinfectionwhen-novel-coronavirus-(ncov)-infectionis-suspected.

18. Chen N, Zhou M, Dong X, Qu J, Gong F, Han Y, et al. Epidemiological and Clinical Characteristics of 99 Cases of 2019 Novel Coronavirus Pneumonia in Wuhan, China: A Descriptive Study. Lancet (2020) 395:507-13. doi: 10.1016/ S0140-6736(20)30211-7

19. Zhou F, Yu T, Du R, Fan G, Liu Y, Liu Z, et al. Clinical Course and Risk Factors for Mortality of Adult Inpatients With COVID-19 in Wuhan, China: A Retrospective Cohort Study. Lancet (2020) 395:1054-62. doi: 10.1016/ S0140-6736(20)30566-3

20. Xie J, Covassin N, Fan Z, Singh P, Gao W, Li G, et al. Association Between Hypoxemia and Mortality in Patients With Covid-19. Mayo Clin Proc (2020) 95:1138-47. doi: 10.1016/j.mayocp.2020.04.006

21. Yao Y, Cao J, Wang Q, Shi Q, Liu K, Luo Z, et al. D-Dimer as a Biomarker for Disease Severity and Mortality in COVID-19 Patients: A Case Control Study. J Intensive Care (2020) 8:49. doi: 10.1186/s40560-020-00466-Z

22. Tian J, Yuan X, Xiao J, Zhong Q, Yang C, Liu B, et al. Clinical Characteristics and Risk Factors Associated With COVID-19 Disease Severity in Patients With Cancer in Wuhan, China: A Multicentre, Retrospective, Cohort Study. Lancet Oncol (2020) 21:893-903. doi: 10.1016/S1470-2045(20)30309-0

23. Varga Z, Flammer AJ, Steiger P, Haberecker M, Andermatt R, Zinkernagel AS, et al. Endothelial Cell Infection and Endotheliitis in COVID-19. Lancet (2020) 395:1417-8. doi: 10.1016/S0140-6736(20)30937-5

24. Zhang B, Yu Y, Hubert SM, Zhang Y, Lu J, Liu S, et al. Prognostic Value of Pro-Inflammatory Neutrophils and C-Reactive Protein in Cancer Patient With Coronavirus Disease 2019: A Multi-Center, Retrospective Study. Front Pharmacol (2020) 11:576994. doi: 10.3389/fphar.2020.576994

25. Suetrong B, Walley KR. Lactic Acidosis in Sepsis: It's Not All Anaerobic: Implications for Diagnosis and Management. Chest (2016) 149:252-61. doi: $10.1378 /$ chest.15-1703

26. Nguyen HB, Rivers EP, Knoblich BP, Jacobsen G, Muzzin A, Ressler JA, et al. Early Lactate Clearance is Associated With Improved Outcome in Severe Sepsis and Septic Shock. Crit Care Med (2004) 32:1637-42. doi: 10.1097/ 01.ccm.0000132904.35713.a7
27. Doherty JR, Cleveland JL. Targeting Lactate Metabolism for Cancer Therapeutics. J Clin Invest (2013) 123:3685-92. doi: 10.1172/JCI69741

28. Ok F, Erdogan O, Durmus E, Carkci S, Canik A. Predictive Values of Blood Urea Nitrogen/Creatinine Ratio and Other Routine Blood Parameters on Disease Severity and Survival of COVID-19 Patients. J Med Virol (2021) 93:786-93. doi: 10.1002/jmv.26300

29. Qin C, Wei Y, Lyu X, Zhao B, Feng Y, Li T, et al. High Aspartate Aminotransferase to Alanine Aminotransferase Ratio on Admission as Risk Factor for Poor Prognosis in COVID-19 Patients. Sci Rep (2020) 10:16496. doi: 10.1038/s41598-020-73575-2

30. Wang Q, Zhao H, Liu LG, Wang YB, Zhang T, Li MH, et al. Pattern of Liver Injury in Adult Patients With COVID-19: A Retrospective Analysis of 105 Patients. Mil Med Res (2020) 7:28. doi: 10.1186/s40779-02000256-6

31. Cheng L, Li H, Li L, Liu C, Yan S, Chen H, et al. Ferritin in the Coronavirus Disease 2019 (COVID-19): A Systematic Review and Meta-Analysis. J Clin Lab Anal (2020) 34:e23618. doi: 10.1002/jcla.23618

32. Xu X, Yu C, Qu J, Zhang L, Jiang S, Huang D, et al. Imaging and Clinical Features of Patients With 2019 Novel Coronavirus SARS-Cov-2. Eur J Nucl Med Mol Imaging (2020) 47:1275-80. doi: 10.1007/s00259-02004735-9

33. Lee LY, Cazier JB, Angelis V, Arnold R, Bisht V, Campton NA, et al. Covid-19 Mortality in Patients With Cancer on Chemotherapy or Other Anticancer Treatments: A Prospective Cohort Study. Lancet (2020) 395:1919-26. doi: 10.1016/S0140-6736(20)31173-9

Conflict of Interest: The authors declare that the research was conducted in the absence of any commercial or financial relationships that could be construed as a potential conflict of interest.

Copyright (C) 2021 Asghar, Abu Bakar, Akram, Farooq, Siddique, Rana, Ali, Rashid, Khan and Loya. This is an open-access article distributed under the terms of the Creative Commons Attribution License (CC BY). The use, distribution or reproduction in other forums is permitted, provided the original author(s) and the copyright owner(s) are credited and that the original publication in this journal is cited, in accordance with accepted academic practice. No use, distribution or reproduction is permitted which does not comply with these terms. 